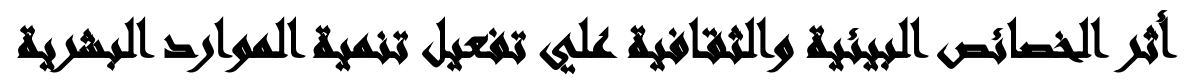

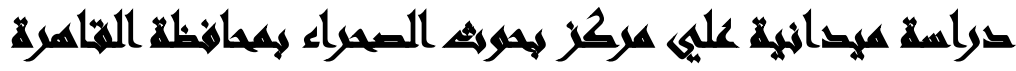

$[\mathrm{V}]$

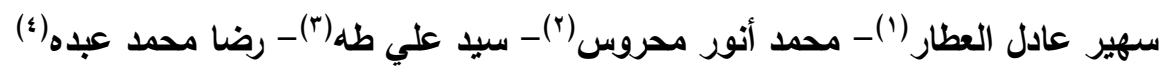

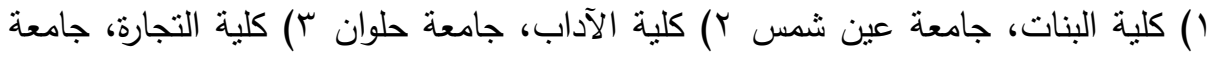
المنوفية ؟) المركز الاستشاري الدولي عائي

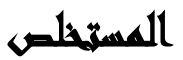

تنتهدف هذه الدراسة الي التعرف علي أثر الخصائص البيئية والثقافة علي تفعيل تتمية

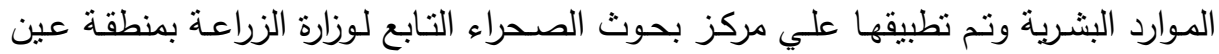

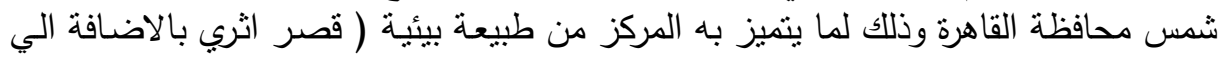

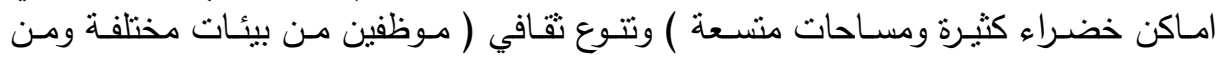

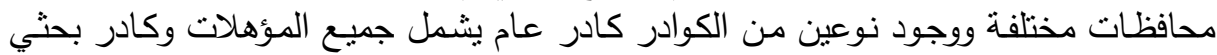

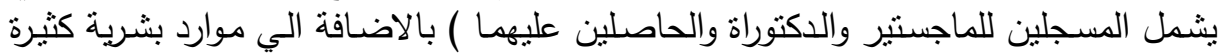

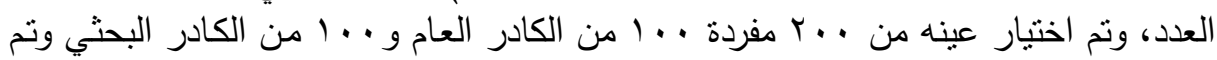

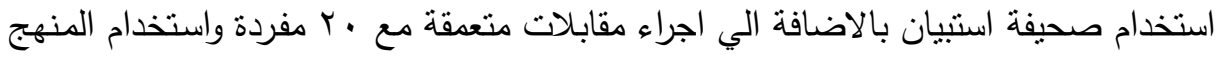

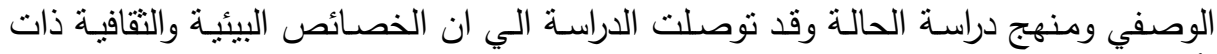

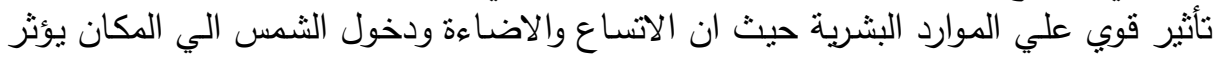

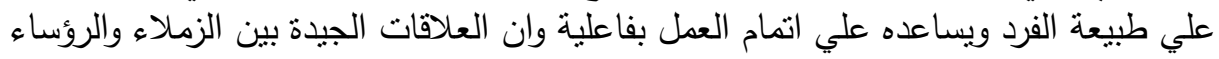

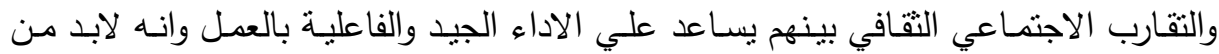

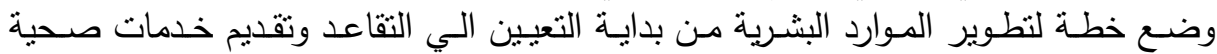
واجتماعية وثقافية وتعليمية للموظفين.

\section{المهinan}

يعتبر العنصر البشري هو أحد أهم العناصر الحاكمه فى التطور والتتمية الاجتماعية والاقتصادية، كما أنه المستقبد النهائي من عملية التتمية، من هذا المنظور فان تتمية الموارد البشرية هي السبيل الي التتمية واداتها والهدف منها في نفس الوقت، والتتمية كمفهوم عام

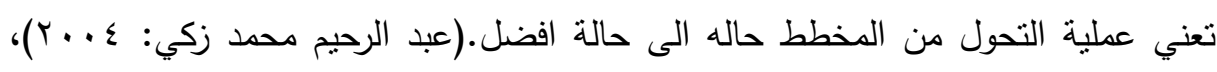

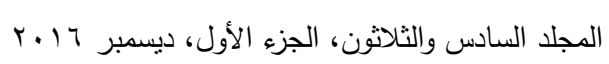


وتستتد مقومات التنمية البثرية علي الابعاد الانسانية والاقتصادية والاجتماعية والثقافية

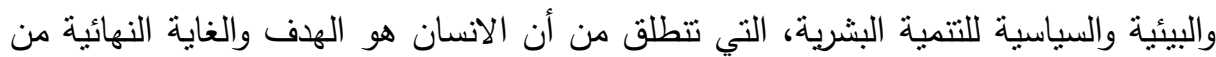

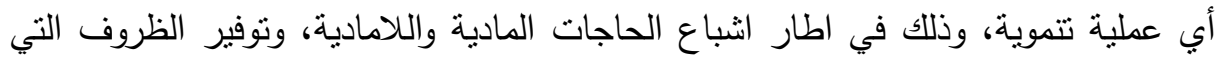
تعمل علي الاستمتاع بما يعرف باسم كرامة الانسان واشباع الحاجات الانسانية اللازمة الانة

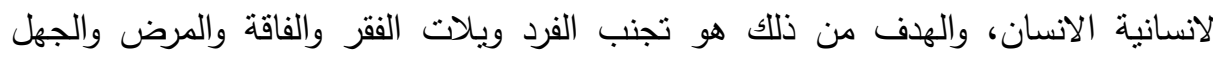
والتهميش، وتمكينة من الاستمتاع بالأمن وتوفير فرص المشاركة في جميع مناحي الحياة.

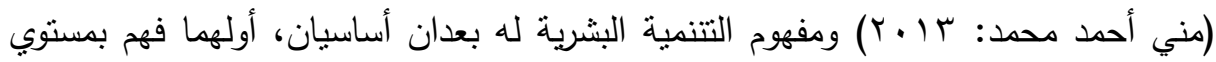
حالة النمو الانساني في مختلف مراحل الحياة، وهو مكون قدرات الانسان وطاقاته البدنية والعقلية والتتشئة الاجتماعية والمهارية والروحية، من خلال ما يتطلبه الاثباع المتتامي لمختلف احتياجاته، ذلك النمو بعناصره المادية وغير المادية، ومن ثم فان الكينونة الراهنه والصيرورة المنشودة لحالة الانسان، تكونان معا هذا البعد الأول. والبعد الثاني للمفهوم يتمثل

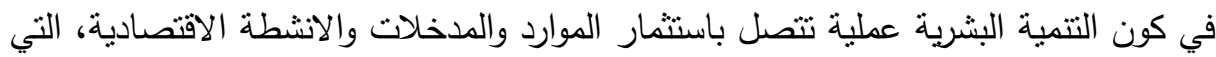

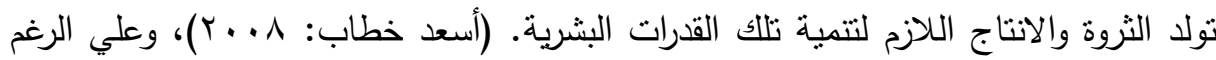

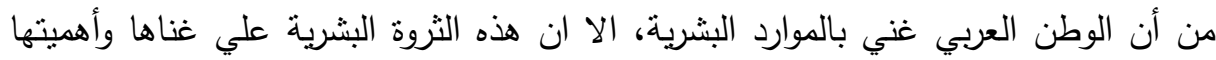

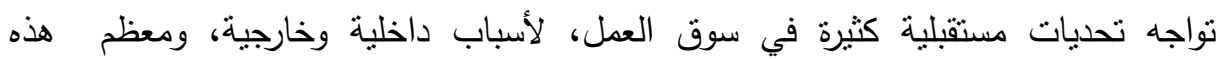
التحديات فرضنها العولمة ودخول العالم عصر الثورة المعلومانية في مراحلها الفائقة، هذا بالاضافة الي بعض التحديات الذاتية والموضوعية الداخلية، وهذا الواقع افرز تحديات جديدة أمام الموارد البشرية العربية ولكن مع ذلك فان بروز هذه التهات التحديات يمكن ان يكون حافزاً

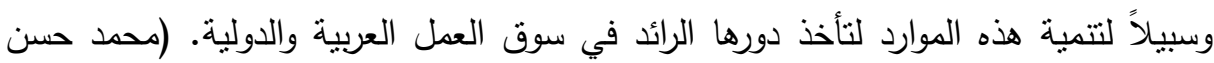

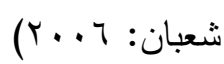

\section{مئم التواسم}

تكمن مشكلة الدراسه فى التعرف علي" مدي نأثنير الخصائص البيئية والثقافية علي تفعيل

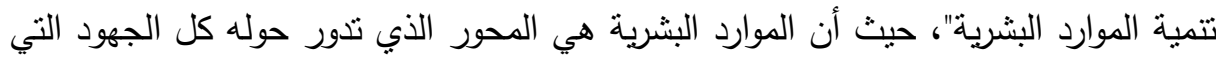
تهدف الي التتمية، فالعنصر البشري في النهاية هو الذي سيوظف كل القدرات لاتخاذ القرارات 
الرشيدة، ويقوم بتتفيذها ومتابعتها وتطوير العمل وتحسين الاداء للوصول الى الاهداف المرجوة بكفاءة وفاعلية، خاصة في مجال البيئة حيث انها الاساس الذي يعتمد عليه مفهوم التتمية

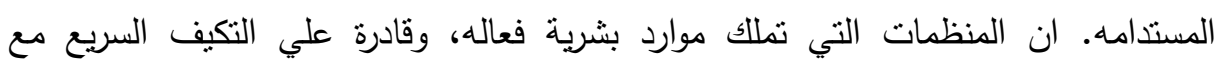

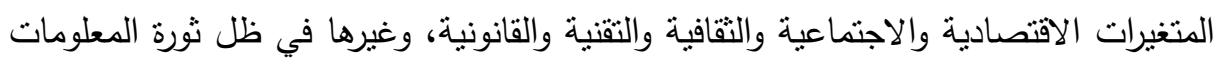

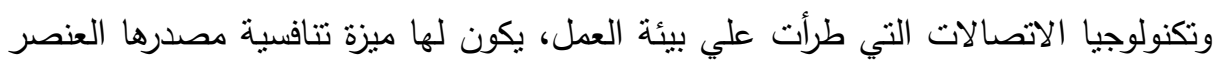
البشري المدرب، والقادر علي التعامل الايجابي مع التغيير الذي قد ينتج من المتغييرات البيئية

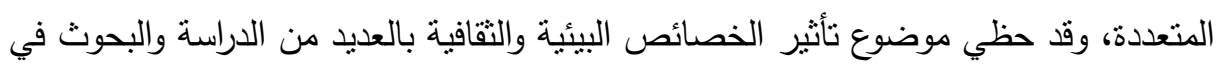

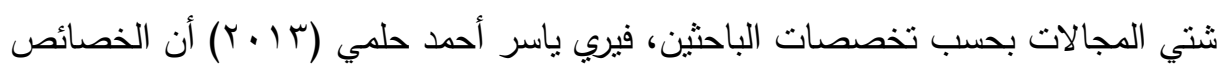

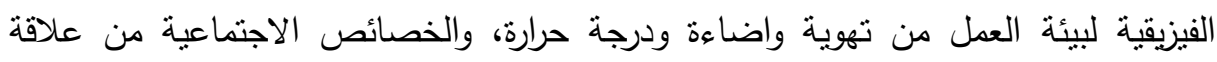

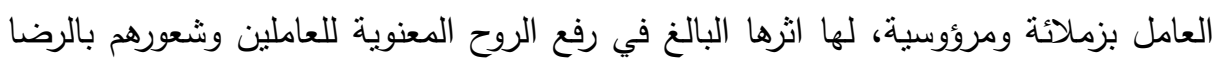
الوظيفي. وأيضا دراسة أمل محمد موسي (Y. . . V) لاثر المتغيرات الاجتماعية المرتبطة بييئة العمل وأثرها علي انتاجية الفرد وتوصلت الي وجود مجموعه من العوامل التي تسهم في اثراء

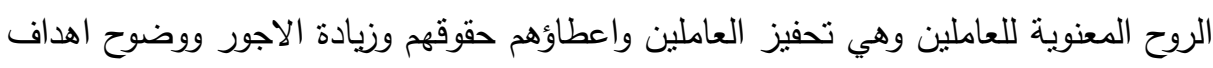

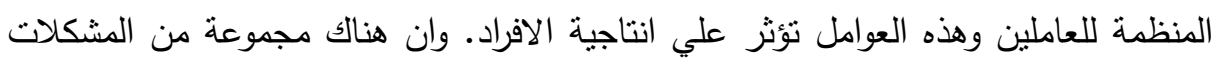

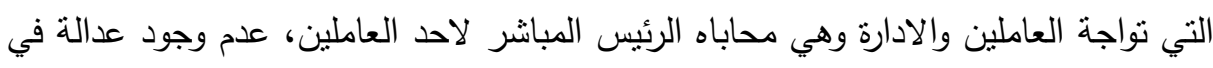

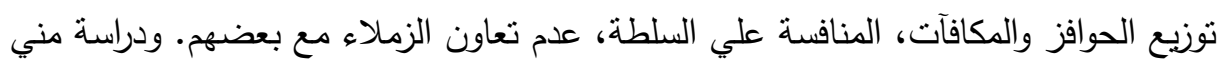

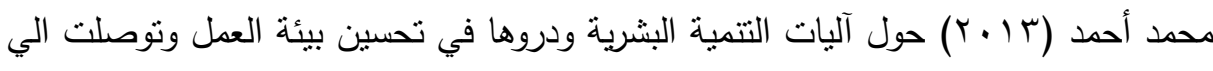
أن اهم المشكلات الادارية التي تؤثر علي اداء العنصر البشرية داخل المؤسسة في عدم وجود عدالة اجتماعية بين العاملين بالاضافة الي عدم وجود قنوات اتصال بين العاملين والادارة الداء.

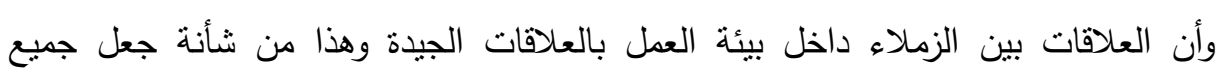
العاملين يعملون في ظل مناخ جيد وملائم. وقد قام الباحثون بعمل دراسة أسنطلاعية بمركز

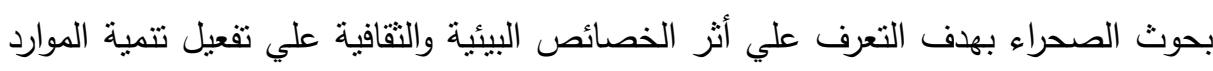
البشرية بالمركز وقد اتضح خلالها ان الخصئاص البيئية بالاضافة الي التتوع الثقافي الموجود لتئيه بالمركز برتبط بتتمية الموارد البشرية بالمكان وهو ما استدعي قيام الباحثون بدراسته تفصيلا.

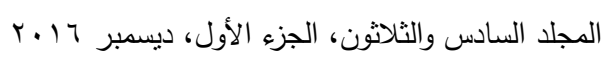




\section{تمساولايت السراسما}

في إطار التحديد السابق لمشكلة الدراسة، وفي محاولة الوصول الي العلاقة بين الخصائص البيئية والثقافية وتتمية الموارد البشرية، يمكن بلورة التساؤلات التالية:

1- ما الخصائص البيئية والثقافية المرنبطة بتتمية الموارد البشرية ؟ r- الي اي مدي تؤثز الخصائص البيئية والثقافية علي تفعيل تتمية الموارد البشرية؟

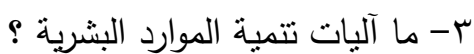

\section{أهداهي الدواسم}

$$
\text { يمكن بلورة أهم أهداف الدراسة فيما يلي: }
$$

- - معتعرف علي الخصائص البيئية والثقافية المرتبطة بتنمية الموارد البثرية. - - معرفة الي اي مدي تؤثر الخصائص البيئية والثقافية علي تفعيل تتمية الموارد البشرية. - - التعرف علي آليات تتمية الموارد البشرية.

\section{أهمية التواسمة}

تأقسم أهمية الدراسة الى نوعين:

أ- الأهمية النظرية: وتتمتل الأهمية النظرية للاراسة في النقاط التالية: - رصد كافة الظواهر التي تؤُثر على تتمية المجتمع. - - إثراء التراث الأجتماعي بدراسات منهجية علمية في الدراسات الأجتماعبة والبيئية.

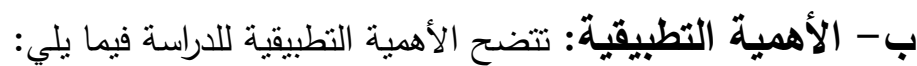
- - العمل علي حل المشكلات التي تحول دون تتمية المجتمع بشكل عام. - - مشاركة البحث العلمي في تتمية المجتمع ووضع النظريات العلمية موضع النطبيق. 


\section{مهاهيه السراسمة}

ا - البيئة: لما كانت البيئة تشمل الجانبين المادي والمعنوي فانه يحسن الآخذ بالتعريف التالي لثموليتة للجانبين: فالبيئة " هي الكل المتكامل من الانسان والكائنات الحية الاخري والمواد، وما بينها من علاقات وتفاعل ونتائج يؤثر بعضها علي بعض، ويتأثر كل منها

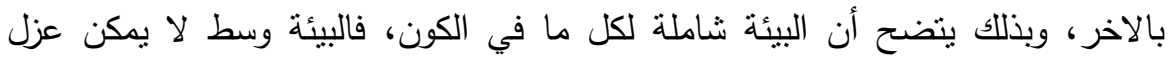
مكوناتة عن بعضها البعض فهي دائمة التفاعل تأثنرا وتأثرا." (محمد أنور محروس:V . . . إ)، ويعرف برنامج الامح المتحدة البيئة بانها " الأطار الذي يحيا فيه الانسان ضمن مجموعة من النظم الطبيعية والاجتماعية والثقافية التي تتكل الدورة الحياتية للانسان والكائنات الأخري". (حسين طه نجم وآخرون: \&191()، ويتضمن تعريف البيئة

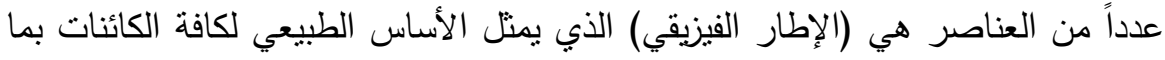
فيها الانسان. و (الإطار الإجتماعي) الذي يمثل الأفراد والجماعات والمجتمعات، وما

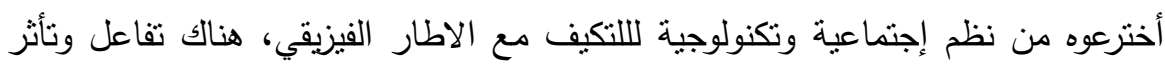
منبادل بين الإطار الفيزيقي والإجتماعي، وينعكس علي الإنسان في مختلف الجوانب الثقافية والسياسية والإقتصادية والصحية، وبالنالي فهي تثير سلوك الفرد والجماعة

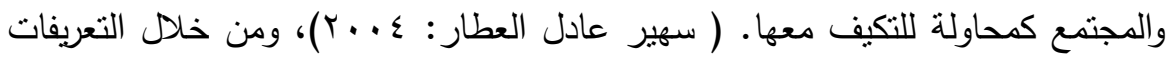
السابقة قام الباحث بوضع تعريف إجرائي للبيئة كالتالي: " هي ذللك الاطار الذي يحيا فيه الانسان ويحيط به من ماء وهواء وارض ويتعامل فيه ويتفاعل مع غيره من الكائنات الحية

r - الثقافة: تتكون الثقافة من أنماط النشاط الانساني المكتسبة والمتوارثة أجتماعيا، ومن الاثياء " العناصر المادية " المرتبطة بها، وأهم شئ يجب أن نعرفة أن الثقافة تعني دائما المعرفة الفنية لثئ ما، كيف نزرع القمح، كيف ننظم حفل الزفاف، كيف تسنخدم فعلا معينا في اللغة في صيغة المستقبل و المصطلحات المرتبطة به. ( سهير عادل العطار:

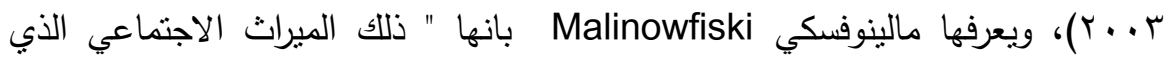

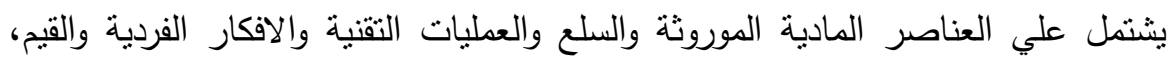

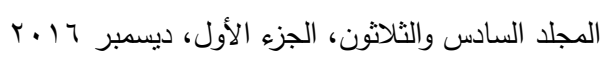


ويعتبرها وسائل أدائية فعالة يكون الانسان عن طريقها في وضع أفضل يساعده علي الاحاطة بالمشاكل الملموسة التي تواجهة في بيئية، وهو في سباق وكفاح من أجل أثنباع

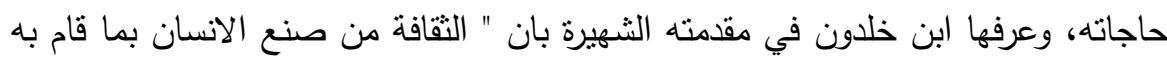

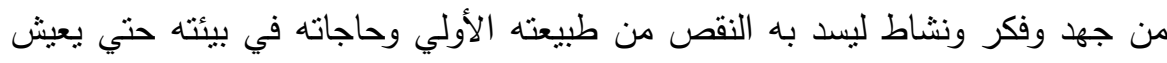

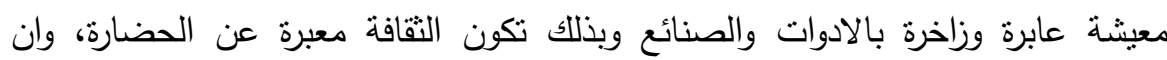
الحضارة تعكس الثقافة وتكثف عنها". وذهب نفس المذهب مصطفي الخشاب حيث قرر أن الثقافة تعتبر عنصرا هاما من عناصر التراث الاجتماعي، وتتشمل التقافة ما يتلقاة الفرد من الجماعة من مظاهر الفنون والعلوم والمعارف والفلسفة والعقائد وما اليها.( محمد أنور محروس : ؟991)، ومن خلال التعريفات السابقة قام الباحث بوضع ونع تعريف إجرائي للافقة بانها " كافة انماط السلوك المكتسب والمتوارث اجتماعيا ويشمل العادات والتقاليد والقيم وهي اسلوب للحياة يميز مجتمعا عن غيره. r- التتمية: تعرف التتمية علي أنها " عملية تغير إجتماعي مخطط يقوم بها الإنسان للإنتقال بالمجتمع الي وضع أفضل، وبما يتوافق مع إحتياجاتة وإمكانياتة الإقتصادية

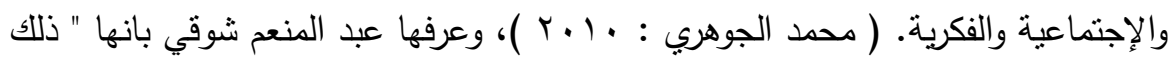
الثنكل المعقد من الإجراءات والعمليات المتتالية والمستمرة التي يقوم بها الإنسان في مجتمع ما من خلال عمل تغير مقصود وموجه بهذف أثباع حاجاته". ( اقبال امير الإليه

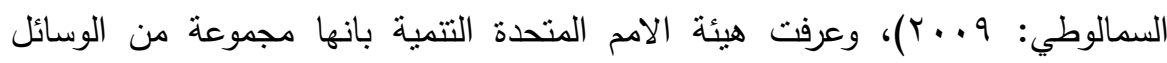
والطرق التي تستخدم بقصد توجية جهود الاهالي مع السلطات العامة لتحسين مستوي الحياة من النواحي الاقتصادية والاجتماعية والثقافية، وتخليص المجتمعات المحلية من عزلتها لتنارك في الحياة القومية وتساهم في التقدم، وتعرف أيضا بأنها " العملية المستمرة

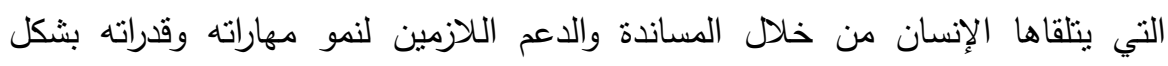
منواصل ومستمر ، ويتم ذلك من خلال عمليات التعلم المخططة أو غير المخططة ولكنها في كل الأحوال تكون ضرورية من أجل نجاح الإنسان في إستثماره لموارده بصورة تتناسب عنب

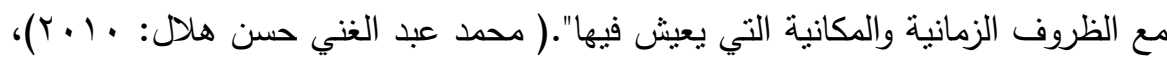


ومن خلال التعريفات السابقة قام الباحث بوضع تعريف إجرائي للتتمية بأنها " عملية

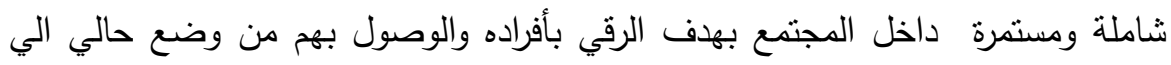
وضع مأمول ومرغوب من تحسين المستوي والتقدم والرقي".

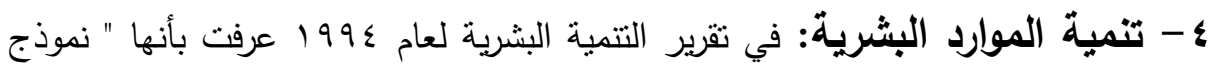

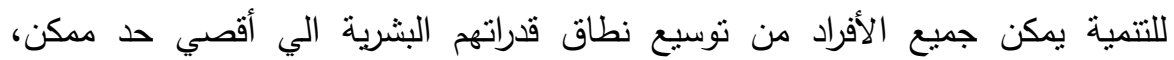
وتوظيف تللك القدرات أفضل توظيف لها في جميع المجالات، وهو أيضا يحمي خيارات

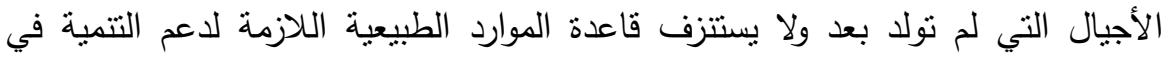

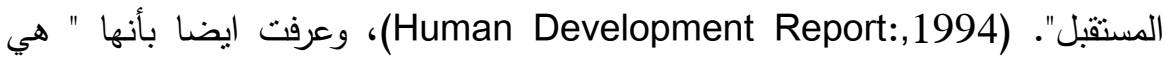
جذب وتتمية الأفراد الذين يملكون المواهب والخيال اللازمين للشركات لكي تتتافس في بيئة متغيرة ومعقدة ". وقيل عن الموارد البشرية أيضا : أنها فن أجتذاب العاملين وأختيارهم وتعيينهم وتتمية قدراتهم وتظوير مهاراتهم وتهئية الظروف التظيمية الملائمة من حيث الكم

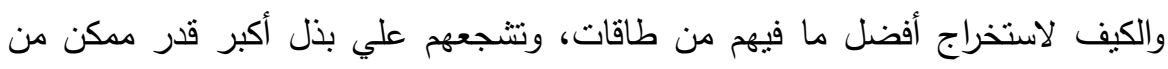

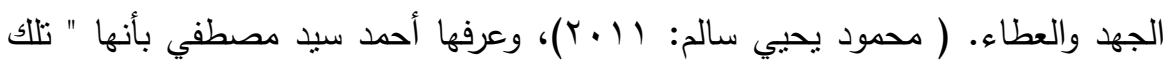

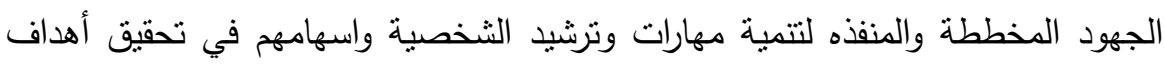
المنظمة".( مدحت ابو النصر : 9 . . F )، ومن خلال ما سبق من تعريفات ثام الباحث بوضع تعريف إجرائي لتنمية الموارد البشرية بأنها " عملية النطوبر والرقي بالعنصر

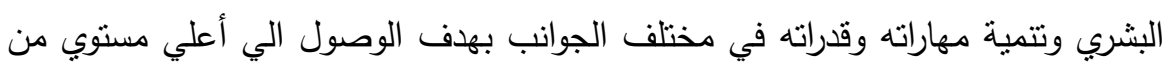

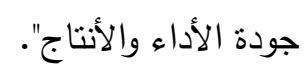

\section{الصراسايت الماريها}

فيما يلي عرض لبعض الدراسات السابقة والتي راعى الباحث فيها التسلسل الزمني من الاحدث إلي الأقدم وقد قسم الباحثون هذه الدراسات إلي محورين:

المحور الأول: الدراسات التي تناولت الخصائص البيئية والثقافية هاتئ

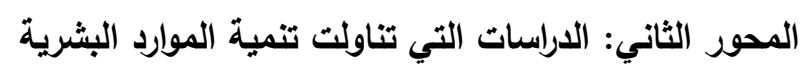

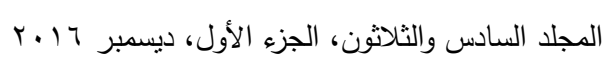




\section{أولاً: الاراسات التي تناولت موضوع الخصائص البيئية والثقافية:}

\section{1- دراسة ياسر أحمد حلمي خميس: الخصائص الاجتماعية والفيزيقية لبيئة العمل وإثرها}

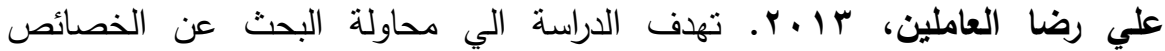
الاجتماعية لبيئة العمل من علاقة العامل بزملائة وعلاقته بمرؤوسية وعلاقة العامل بالادارة العليا بالمصنع وشعور العامل بالرضا عن عمله ودعم الروح المعنية للعاملين، كما تهدف الي محاولة الوقوف علي الفروق بين خصائص بيئتي العمل الفيزيقية والاجتماعية بين القطاعين الحكومي والخاص لمحاولة تفادي هذه الفروق للوصول الي رضا العاملين

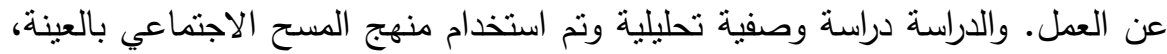
وقد اسفرت عن النتائج التالية:

توصلت الدراسة الي عدد من النتائج الهامه منها ظهور مقياس خصائص بيئة العمل الفيزيقية كأعلي منوسط ونسبة حيث بلغت نسبته س \& \% تقريبا الامر الذي يوضح مناسبة بيئة العمل الفيزيقية وخصائصها بمصانع القطاع الحكومي والخاص. r - دراسة مجدي شريف صالح شريف: بعض العوامل البيئية المسببة للاغتراب في العمل وعلاقته بالرضا الوظيفي، r ا ـr. هدفت الدراسة إلي التعرف علي العوامل المسببة للاغتراب في بيئة العمل وعلاقتها بالرضا الوظيفي، والتعرف علي العوامل البيئية الاسرية

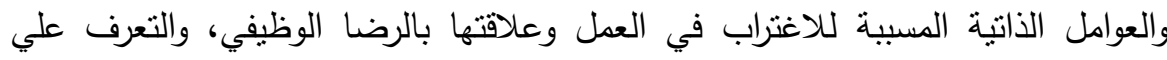

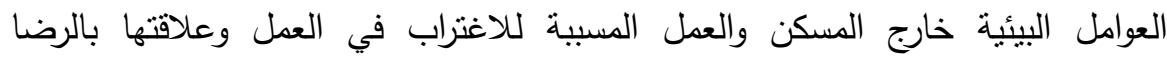
الوظيفي، والتعرف علي أهم ملامح الاغتراب وعدم الرضا الوظيفي وقد اسفرت الدراسة عن أن الاغتراب فى العمل وعدم الرضا الوظيفي هما مخرجات العوامل البيئية غير الهير

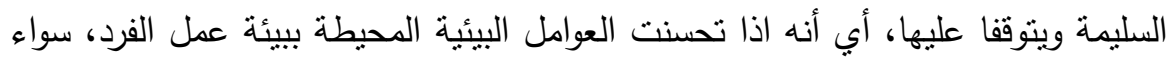

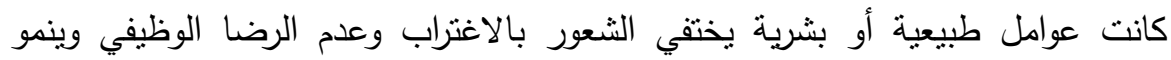

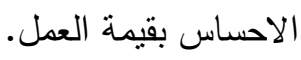


r- دراسة أمل محمد موسي عطية: المتغيرات الاجتماعية المرتبطة ببيئة العمل وآثارها

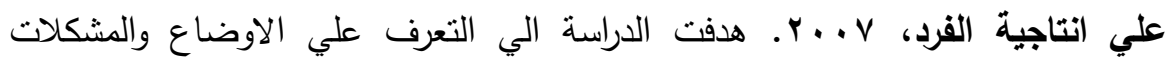

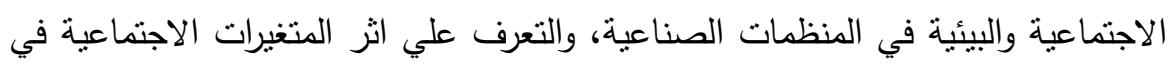
دعم الروح المعنوية لاي العاملين والوقوف علي تأثير هذه المتغيرات علي انتاجية الفرد، والتعرف علي المشكلات الانسانية التي نواجة الادارة العليا من جهة والعاملين من جهة دانير

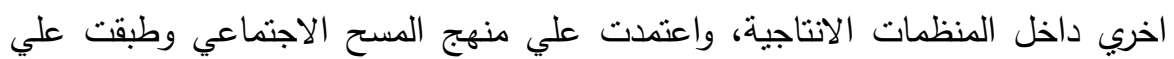
الوحدات الانتاجية بالانتاج الحربي، واسفرت الدراسة عن النتائج الاتية: - وجود مجموعه من العوامل التي تسهم في اثراء الروح المعنوية للعاملين وهي تحفيز العاملين واعطاؤهم حقوقه وزيادة الاجور ووضوح اهداف المنظمة للعاملين وهذه العوامل فئل فئل تؤثثر علي انتاجية الافراد. - هناك مجموعة من المشكلات التي تواجة العاملين والادارة وهي محاباه الرئيس المباشر لاحد العاملين، عدم وجود عدالة في توزيع الحوافز والمكافآت، المنافسة علي السلطة، عدم وله تعاون الزملاء مع بعضهم.

ع - دراسة جاكويسون فيكي:عدائية بيئة العمل اتجاهات الموظفين، مدركاتة، وسلوكياتة

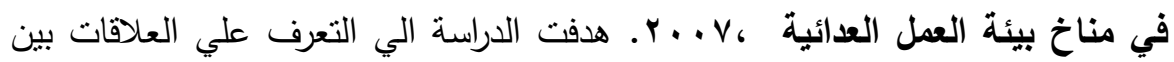
اتجاهات الموظف ومدركاتة الحسية في ظل بيئة عمل عدائية، والالتزام المؤسسي وسلوكيات اعاقة الانجاز وتأثيرات بيئة العمل العدائية علي موظفي المؤسسة. واعتمدت ولهات الدراسة علي المسح فى جمع البيانات وطبقت علي منظمات مينيسونا الصناعية الموفرة لتسهيلات الرعاية الصحية طويلة المدي. وقد أسفرت الدراسة عن النتائج التالية: - ان هناك تعقد شديد في بيئة العمل العدائية وسلوكيات الموظفين السلبية وانقطاعهم عن

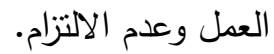




\section{ثانياً: الدراسات التي تناولت موضوع تنمية الموارد البشرية}

1-دراسة مني أحمد محمد: آليات تنمية الموارد البشرية ودورها في تحسين بيئة

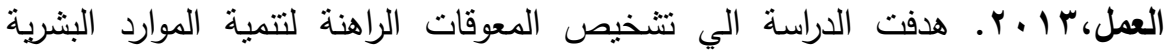
والتعرف علي دور الادارة في تنمية الموارد لبشرية داخل بيئة العمل وماهي مقومات بيئة العئة

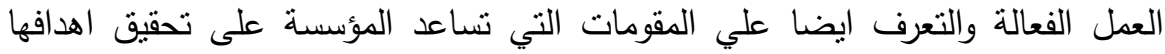

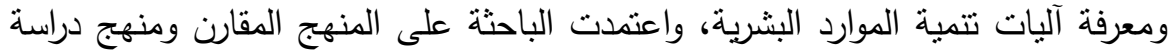

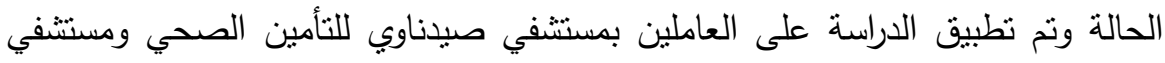
السلام الدولي الخاصة وقد خرجت الدراسة بالننائج التالية:

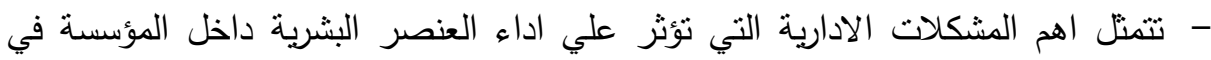

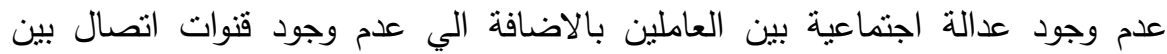
العاملين والادارة. - تتسم لعلاقات بين الزملاء داخل بيئة العمل بالعلاقات الجيدة وهذا من شأنة جعل جميع العاملين يعملون في ظل مناخ جيد وملائم.

r- دراسة افوي زيتا جيزيل كونان: كفاءات تنمية الموارد البشرية من وجها نظر مختصي

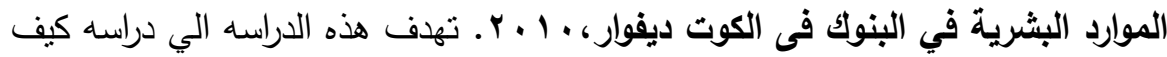

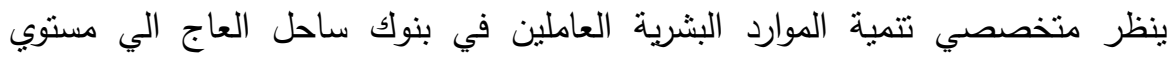
خبراتهم الحالية من كفاءة في تتمية الموارد البثرية وما هي أهم المهارات اللازمة للنجاح التهاح

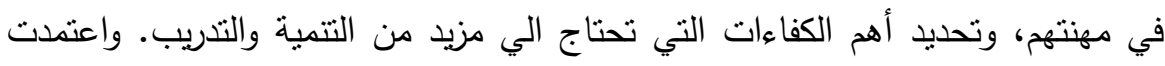

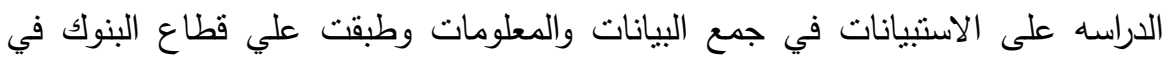

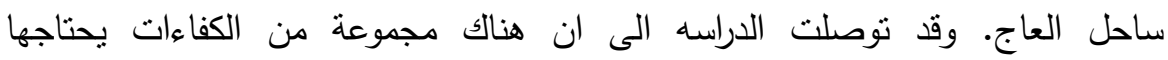

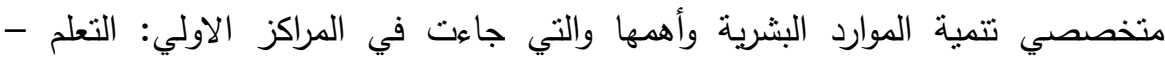
التدريب - القياس والثقييم. تكئ. 
r- دراسة سونج يونهيون: السلوكيات القياديه وتنميه الموارد البشريه في مؤسسات القطاع العام تحت ظروف عدم اليقين التظيمي، دراسه مقارنه بين الولايات المتحده

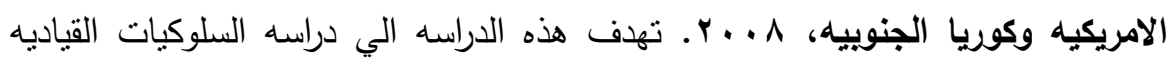
واثرها على تتميه الموارد البشريه تحت ظروف عدم اليقين التتظيمي في المؤسسات العامه، واعتمدت الدراسه على المنهج المقارن بين المؤسسات الحكوميه بالولايات المتحده الامريكية والمؤسسات الحكوميه في الكوريه الجنوبيه. وقد نوصلت الدراسه الى ان للسلوكيات القياديه تأثثر على تتمبه الموارد البشريه حيث انها انخفضت في المؤسسات العامه في البلدين عندما قابلت مستويات عاليه من عدم اليقين

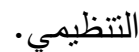
ع - دراسة راشد سويد قران راثد المنصوري: دور التنمية البشرية في تحسين الأداء في

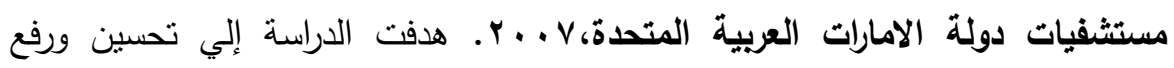

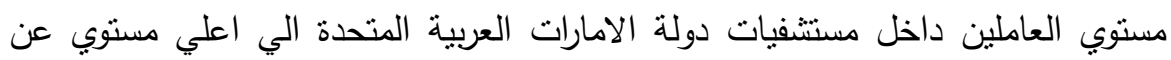

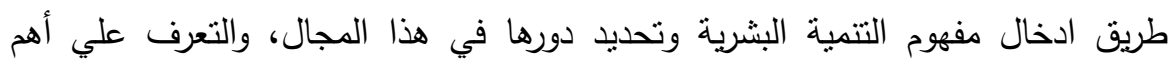
المؤشرات التي تؤخذ في الاعتبار عند وضع خطط تهدف الي رفع كفاءة أداء العاملين، وخلق كوادر جديدة داخل الهيكل التتظيمي لمستشفيات دولة الامارات العربية المتحدة، وقد توصلت الدراسة للنتائج التالية:

- توجد علاقة معنوية ذات دلالة احصائية بين التتمية البشرية واختبار وتعيين العاملين. - توجد علاقة معنوية ذات دلالة احصائية بين التتمية البشرية وسياسة التدريب. - توجد علاقة معنوية ذات دلالة احصائية بين التتمية البشرية والعوامل البيئية.

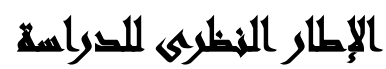

أولاً: نظرية رأس المال البشري: رغم أن نظرية الاستثمار البشري لم تتبلور كنظرية إلا

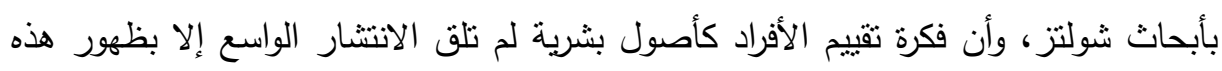

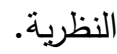


الخصائص الأساسية للرأس المال البشري: يتميز الرأس المال البشري بجملة من الخصائص

$$
\text { - - }
$$

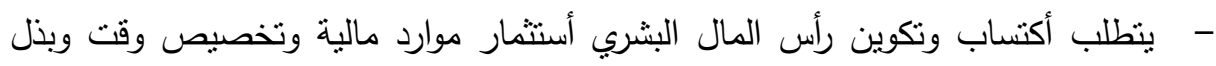

- - يتطور رأس المال البشري بالأستعمال والخبرة في مجال العمل أو عن طريق التطوير

$$
\text { والتعليم. }
$$

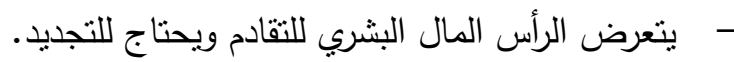

- - يختص الرأس المال البشري بالفرد الذي يكتسبه.

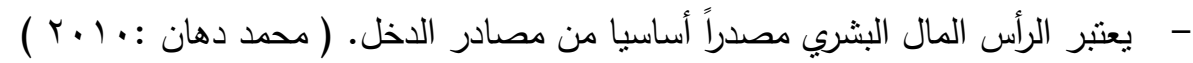
ثانياً: النظرية السلوكية: فيما يلي عرض لمداخل المدرسة السلوكية حيث تحتوي علي لرئي مدخلين هما: مدخل العلاقات الانسانية، مدخل علم السلوك: 1- مدرسة العلاقات الانسانية: ظهرت مدرسة العلاقات الانسانية لدراسة التنظيم الاجتماعي

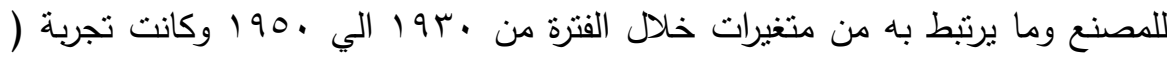

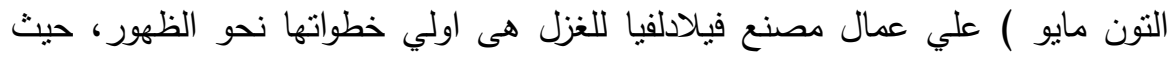

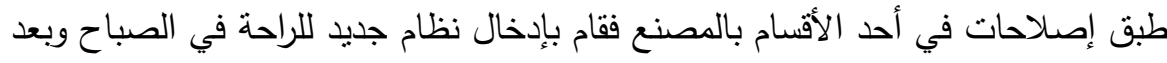

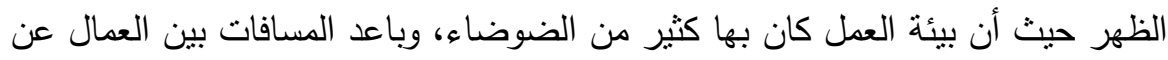
بعضهم والمكافأة التشجيعية عند زيادة الانتاج، فأدت هذه التغيرات الي تحسن الروح

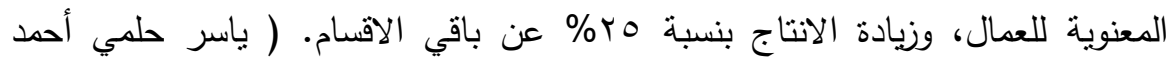

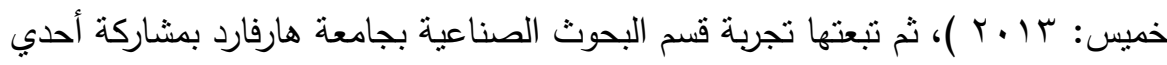

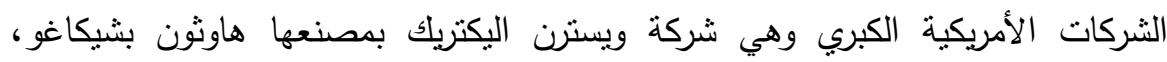
وكانت من أجل أستكثاف العلاقة بين ظروف العمل الفيزيقية والإنتاجية، ثم أنسعت بحيث لثيث 
أصبحت نتتاول جماعات العمل من حيث البناء والروح المعنوية والقيم والاتجاهات

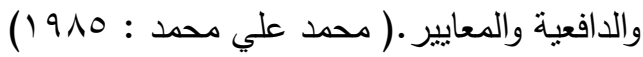

r - مدرسة السلوك الانساني: ركزت النظرية علي ضرورة أنثباع الرغبات الإنسانية للأفراد وذلك كوسيلة لتحسين الإنتاجية وفي هذا الصدد فقد أشنارت مدرسة السلوك الانساني الي الي بعض الوسائل التي تساعد علي توفير ذلك ومنها: تتمية الاتصالات بين الادارة والجماعات المختلفة في التتظيم، تتجيع تكوين الجماعات الاجتماعية في العمل، توفير

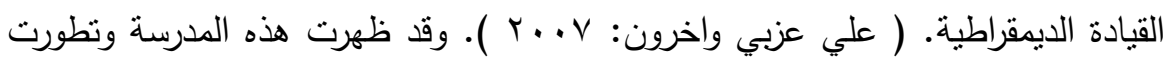
في كتابات كل من جانيت ومونستربرج، وركزت علي الجوانب الخاصة بالإنسان في عملية

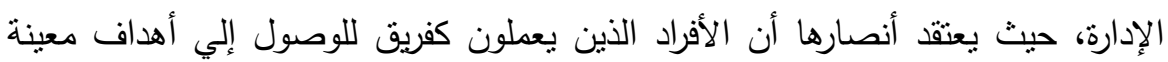

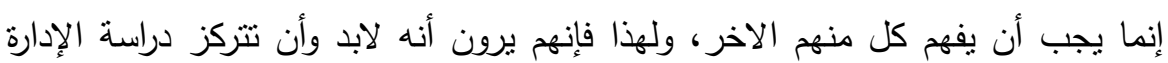
حول العاملين وعلاقاتهم الثخصية فيما بين بعضهم البعض، وقد أدخلت هذه المدرسة

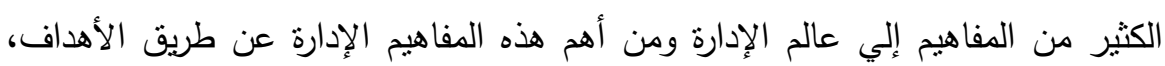

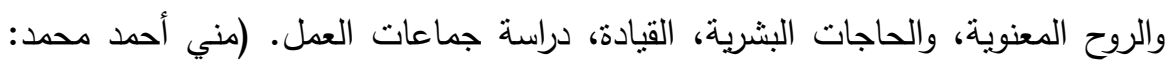

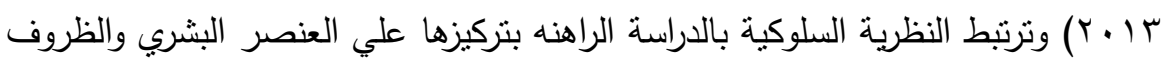

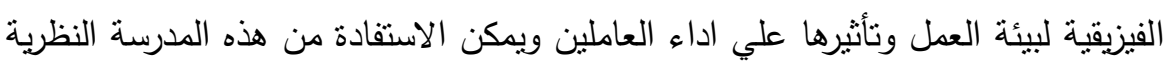

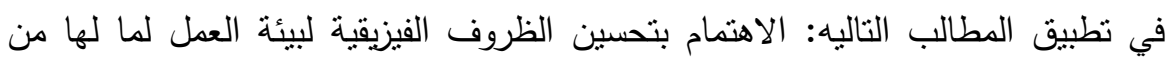
درو في اداء العاملين حتى يتم تتمية ونظوير العنصر البشري. - الاهتمام بالمورد البشري داخل بيئة العمل واعطاؤه العناية اللازمة. - اشباع الرغبات الانسانية للافراد حتى تتحسن الانتاجية.

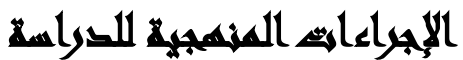

نوع الاراسة: تعتبر هذه الدراسة من الدراسات الوصفية التحليلية، لأنها أنسب أنواع الدراسات الملائمة لطبيعة موضوع الدراسة. منهج الدراسة: اعتمد الباحث في الدراسة الراهنة علي المنهج الوصفي ومنهج دراسة الحالة

$$
\text { المجلد السادس والثلاثون، الجزء الأول، ديسمبر } 17 \text {. }
$$


أدوات الاراسة: استخدم الباحثون لجمع البيانات صحيفة الاستبيان على كافة مفردات العينة، والتى نم من خلالها جمع البيانات اللازمة عن خصائص العينة كالنوع والتعليم والمهن والاخل .... ألخ ثم اشتملت بعد ذلك على أسئلة خاصة بالكثف عن أثز الخصائص البيئية والثقافية علي تفعيل تتمية الموارد البشرية. وتم عمل مقابلات متعقة مع ·r مفردة. وتم تصميم الاستمارة وروعي عند تصميمها عدد الاسئلة وشمولها لجميع المتغيرات التي من المحتمل ان يكون لها علاقة بموضوع الدراسة بطريقة مباشرة أو غير مباشرة وكذلك روعي ان ونهان تكون الاسئلة واضحة ومفهومه من حيث الصياغة، وقد صيغت الاستمارة في شكلها الاول وتم عرضها علي عدد من المحكمين وذلك للتعرف علي ارائهم في صلاحية الاستمارة للهدف الذي صممت من اجله وفي ضوء توجيهاتهم نم تعديل صياغة بعض الاسئلة وحذف البعض

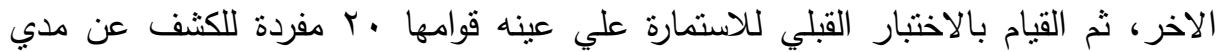
وضوح الاسئلة وفهمها من جانب المبحوثين والوقت المستغرق في استيفاء بياناتها، وفي ضوء هذا الاختبار نم اجراء بعض التعديلات في محتوي الاسئلة، ثم صيغت في شكلها النهائي، وجاءت استمارة الاسنبيان تحتوي علي •ـ سؤالا وفيما يلي عرض لأهم بنود الاستمارة والتي

$$
\text { انحصرت في أربع بنود: }
$$
- بيانات أساسية عن المبحوثين تتضمن الاسم، النوع، الوظيفة، الحالة الاجتماعية،.... الخ. - ما الخصائص البيئية والثقافية المرتبطة بتنمية الموارد البشرية؟ لئن - إلي أي مدي تؤثر الخصائص البيئية والثقافية علي نتمية الموارد البشرية؟

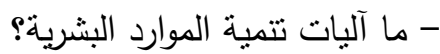

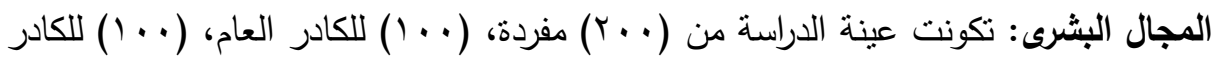

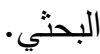
المجال المكانى : مركز بحوث الصحراء - بمنطقة عين شمس - محافظة القاهرة .

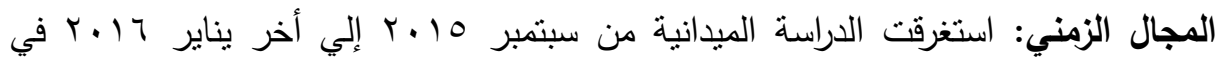

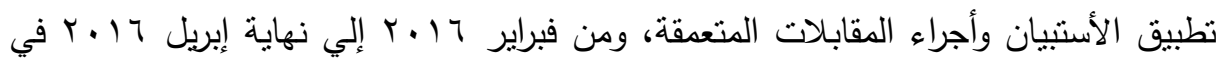
تحليل البيانات الميدانية والوصول إلي نتائج الدراسة. 


\section{نيتائي الصواسمة}

أولاً: الخصائص البيئية والثثافية المرتبطة بتنمية الموارد البشرية

\begin{tabular}{|c|c|c|}
\hline$\%$ & ك & من حيث وصف المركز \\
\hline rq & 01 & واسع \\
\hline $7 \pi .0$ & ITV & متوسط الآتساع \\
\hline$V_{6} 0$ & 10 & ضيق \\
\hline $1 \ldots$ & $r_{\ldots}$ & الإجمالى \\
\hline
\end{tabular}

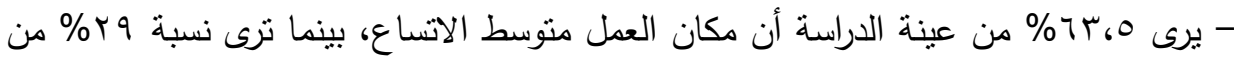

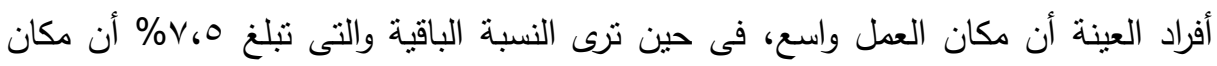

\begin{tabular}{|c|c|c|}
\hline$\%$ & ك5 & من حيث وصف حجرات المركز \\
\hline 11 & ru & واسعة \\
\hline $\mathrm{V} \varepsilon$ & $1 \leq \Lambda$ & متوسطة الاتساع \\
\hline$\Lambda$ & 17 & ضيقة \\
\hline $1 \cdots$ & Y.. & الإجمالي \\
\hline
\end{tabular}

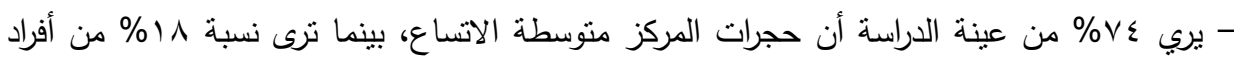

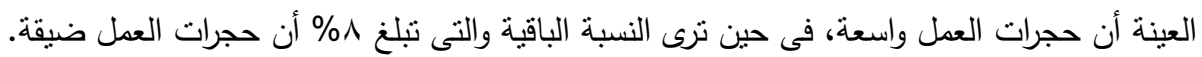

\begin{tabular}{|c|c|c|}
\hline$\%$ & ك & لسمات الطبيعية للمركز \\
\hline Y Y 60 & $\leqslant 0$ & فسيح الأرجاء \\
\hline$\varepsilon \varepsilon 60$ & 19 & به حدائق وآثنجار \\
\hline r & 77 & تخخله الثمس \\
\hline $1 \ldots$ & r.. & الإجمالى \\
\hline
\end{tabular}

- يري 0، §٪ من عينة الدراسة أن وجود الأثجار والحدائق من السمات الطبيعية للمركز ،

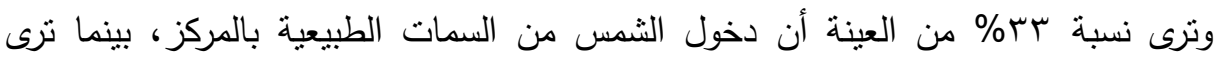

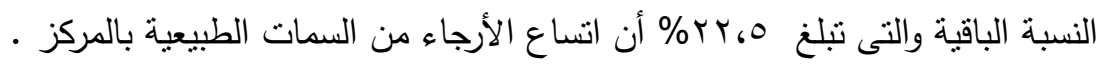

\begin{tabular}{|c|c|c|}
\hline$\%$ & ك & السمات الثقافية للمركز \\
\hline 07 & 114 & بـه مكتبة \\
\hline 19 & $\mu \lambda$ & به استراحة \\
\hline ro & 0 . & به مصلي \\
\hline $1 \ldots$ & r.. & الإجمالي \\
\hline
\end{tabular}

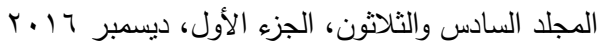


- يري 07\% من عينة الدراسة أن وجود المكتبة من السمات الثقافية والضرورية للمركز ، وترى

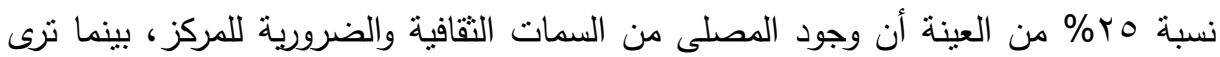
النسبة الباقية والتى تبلغ 9 1\% أن وجود الاستراحة من السمات النقافية والضرورية للمركز وتثنير البيانات السابقة إلى نتوع السمات التقافية بالمركز وهو الأمر الذى يؤثر إيجابًا فى بيئة

ثانياً: مدي تأثير الخصائص البيئية والثقافية علي تفعيل تثمية الموارد البشرية

\begin{tabular}{|c|c|c|}
\hline$\%$ & ك5 & مشكلات العمل \\
\hline 1 . & $r$. & عدم الإضاءة الجيدة \\
\hline 0 & 1. & لا يوجد نوافذ \\
\hline 9.0 & 19 & لا تدخله الثمسر \\
\hline$V 0,0$ & 101 & آخرى (تذكر ) \\
\hline $1 \ldots$ & Y.. & الإجمالى \\
\hline
\end{tabular}

- - م م مشكلات العمل تكمن فى أثنياء أخرى غير مرتبطة بالبيئة الطبيعية مثل عدم توافر الأجهزة المعملية وعدم نوافر الدعم المادى اللازم لإجراء الأبحاث، وترى نسبة ـ 1\% أن عدم

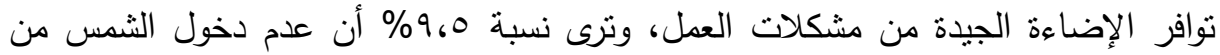
المشكلات التى تواجهم فى العمل، وترى نسبة ه\% أن عدم وجود نوافذ من المشكلات

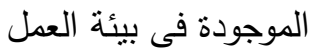

\begin{tabular}{|c|c|c|}
\hline$\%$ & (5) & نوع العلاقة بين الرئيس والمرووس \\
\hline $\mathrm{V}$. & $1 \leqslant$. & احتراح وتعاون \\
\hline 10 & $r$. & لالمبالاه \\
\hline 1 . & r. & تعالى وتكبر \\
\hline 0 & 1 . & استهنار \\
\hline$\ldots$ & r.. & 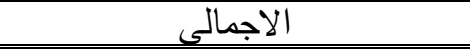 \\
\hline
\end{tabular}

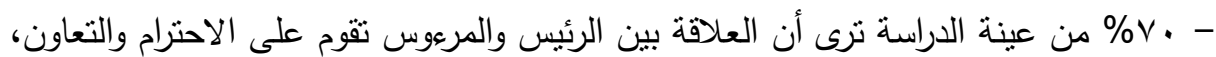

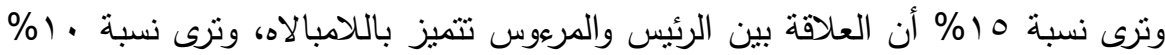
أن العلاقة بين الرئيس والمرعوس فيها تعالى وتكبر، وترى نسبة ه\% أن العلاقة بين الرئيس والمرعوس تتسم بالاستهنار . 
سهير عادل العطار وآخرون

\begin{tabular}{|c|c|c|}
\hline$\%$ & ك & طبيعة العلاقة بين الزملاء \\
\hline$\lambda V_{6} 0$ & 180 & احترام وتعاون \\
\hline$r_{6} 0$ & 0 & لا مبالاه \\
\hline$r$ & $\varepsilon$ & تعالي وتكبر \\
\hline$\Lambda$ & 17 & استختار \\
\hline $1 \cdots$ & $r \ldots$ & الإجمالي \\
\hline
\end{tabular}

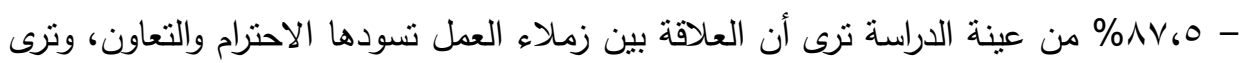

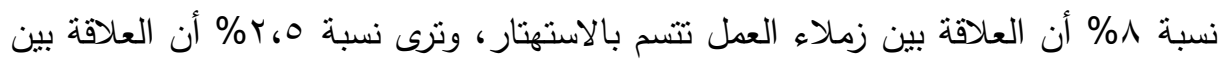

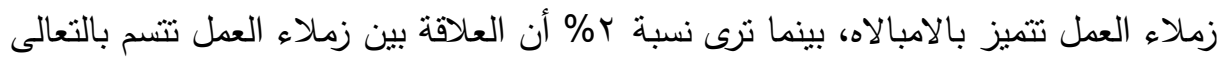

والتكبر

ثالثاً: آليات تثمية الموارد البشرية

\begin{tabular}{|c|c|c|}
\hline$\%$ & "5 & طريقة التوظيف في المركز \\
\hline$\varepsilon 1,0$ & $\Delta r$ & إعلانات \\
\hline 10 & $r$. & اخّتبارات \\
\hline To, & V) & آبناء العاملين \\
\hline$\Lambda$ & 17 & التعبين المباشر \\
\hline $1 \ldots$ & r.. & الإجمالى \\
\hline
\end{tabular}

- 0، 1\% من عينة الدراسة نرى أن التوظيف فى مركز البحوث يتم عن طريق الإعلانات، وترى نسبة 0، 0\% أن التوظيف فى مركز البحوث يتم عن طريق تعيين أبناء العاملين، وترى نسبة 10\% أن التوظيف فى مركز البحوث يتم عن طريق الاختبارات، بينما ترى

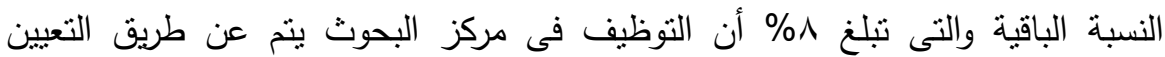
المباشر • وتدل البيانات السابقة أن التوظيف من الممكن أن يكون عن طريق أبناء العاملين وهو ما يؤثز سلبًا إذا كان أبناء العاملين غير مؤهلين لهذا العمل، كما تدل البيانات أهمية نوافر الخبرة والتخصص لتحسين العمل.

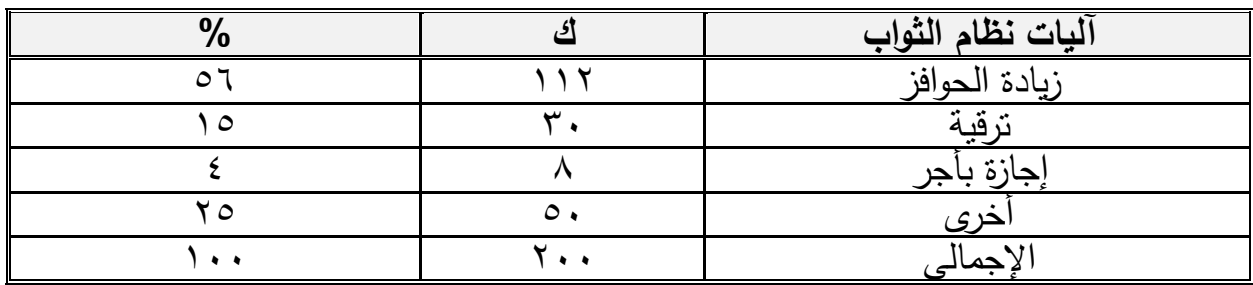


- ـ \% من عينة الدراسة نرى أن زيادة الحوافز من آليات نظام الثثاب فى المركز ، وترى نسبة

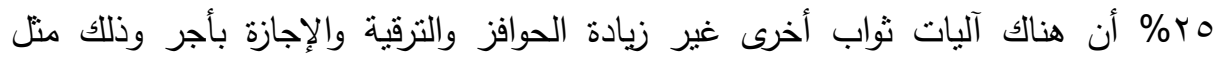

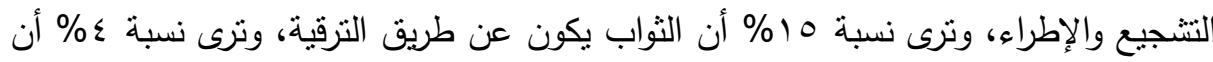

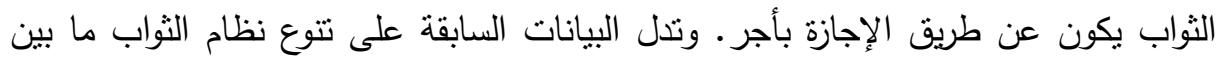

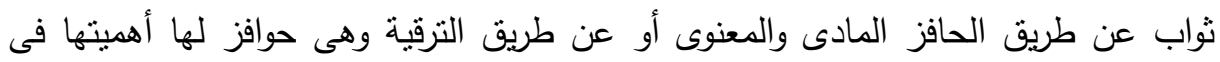

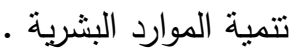

\begin{tabular}{|c|c|c|}
\hline$\%$ & ك & معيار الكفاءة \\
\hline$r \leqslant 60$ & ₹9 & الانتكار والانداع \\
\hline 07 & $\pi r$ & التفاني في العمل \\
\hline TY & $T \varepsilon$ & اللباقة \\
\hline$V_{6} 0$ & 10 & أخرى \\
\hline $1 \ldots$ & r.. & الإجمالى \\
\hline
\end{tabular}

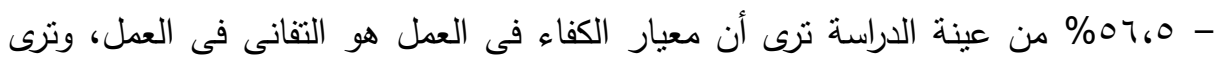

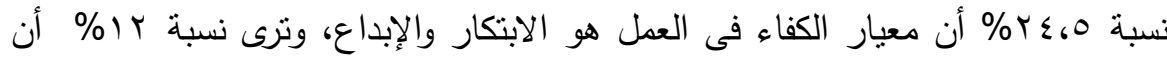

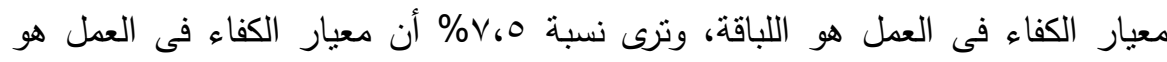
أنشياء أخرى مثل إنجاز العمل فى كل الظروف والتعامل الجيد مع المتابعين والرؤساء.

\begin{tabular}{|c|c|c|}
\hline$\%$ & ك & آساليب تظوير الآداء \\
\hline IT & $T \Sigma$ & تعلبم \\
\hline 77.0 & Tr & تدربب \\
\hline 17.0 & Tr & منح \\
\hline 0 & 1. & أخرى أ \\
\hline $1 \ldots$ & $Y_{\ldots}$ & الإجمالى \\
\hline
\end{tabular}

- -

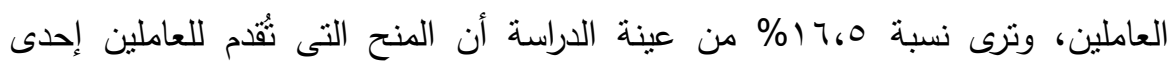

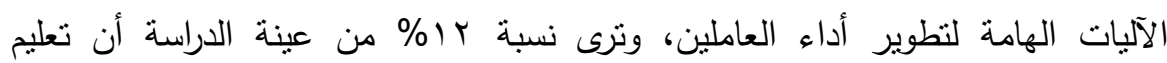

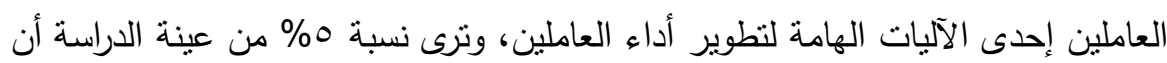
هناك آليات أخرى لنطوير أداء العاملين منل السفر إلى الخارج لاكتساب الخبرة فى العمل. 


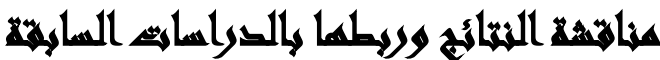

\section{أولاً: الخصائص البيئية والثقافية المرتبطة بتنمية الموارد البثرية:}

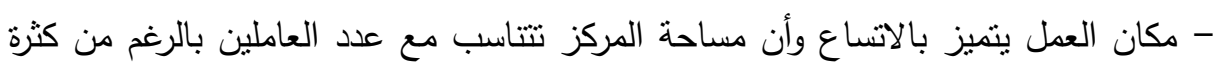

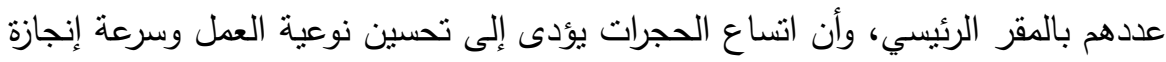

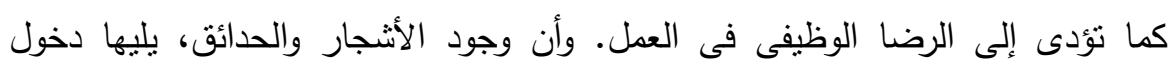

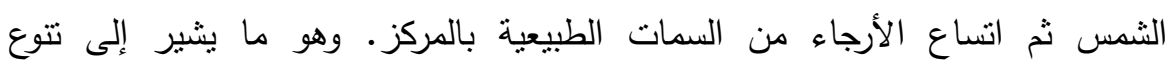

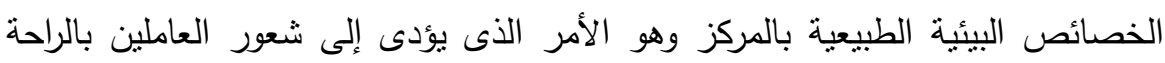

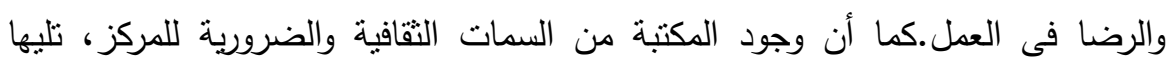

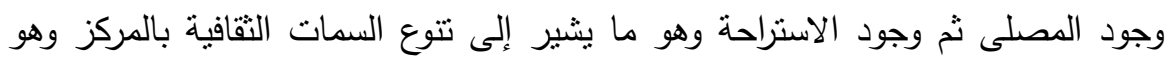

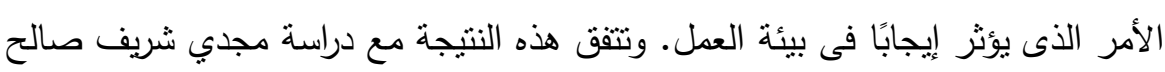

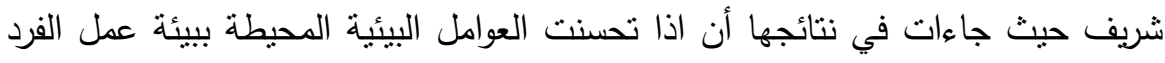

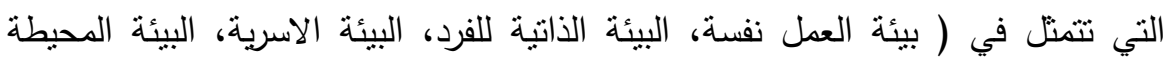

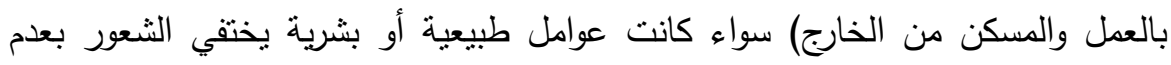
الرضا الوظيفي وينمو الاحساس بقيمة العمل.

ثانياً: مدي تأثثر الخصائص البيئية والثقافية علي تفعيل الثنية الثية الموارد البشرية

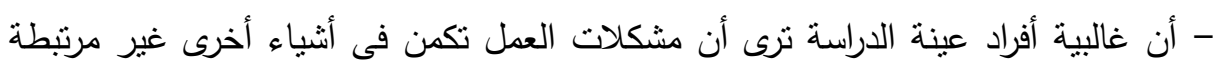

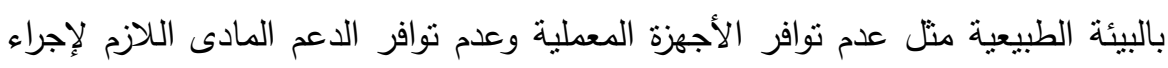

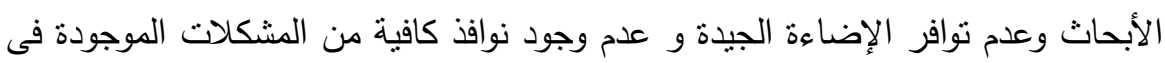

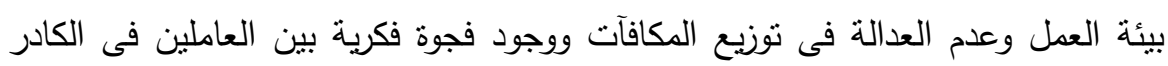
العام والكادر الخاص. وأن غالبية عينة الدراسة ترى أن العلاقة بين زملاء العات العمل تسودها

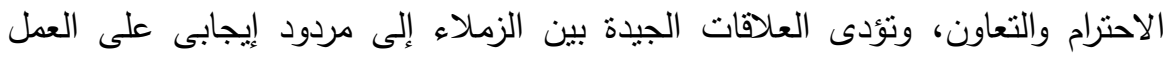

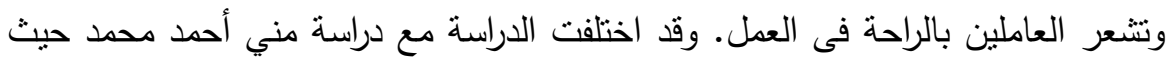

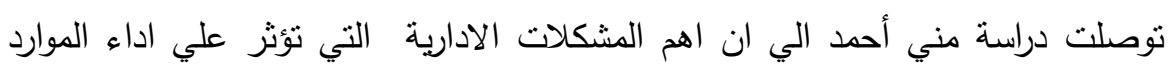

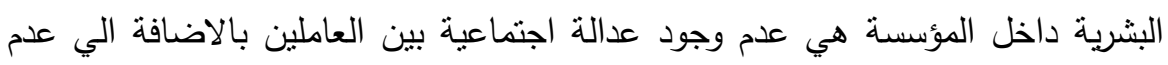

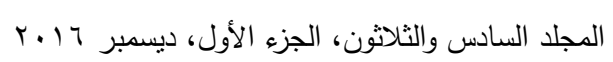


وجود قنوات اتصال بين العاملين والادارة، بينما توصلت الدراسة الحالية ان أهم المشكلات

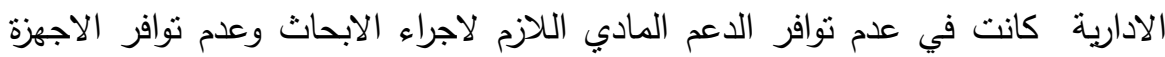
المعملية وعدم العدالة في توزيع المكافأت.

- أن مبحوثى الكادر العام ترى أن العلاقة بين الرئيس والمرعوس يسودها التوافق ولكنها

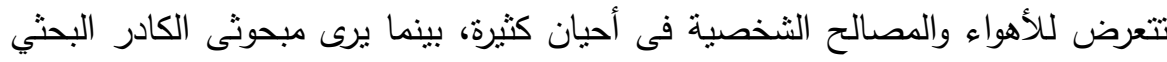

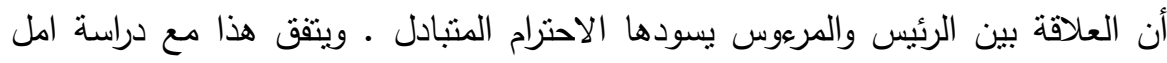

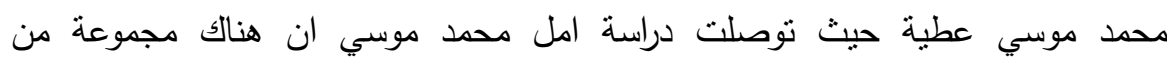
المشكلات التي نواجة العاملين والادارة وهي محاباه الرئيس المباشر لبعض العاملين، وعدم وجود عدالة في توزيع الحوافز والمكافأت.

ثالثاً: آليات تنمية الموارد البشرية:

- أن التوظيف الذى ينم عن طريق الإعلانات واختيار الأكفأ هو المناسب للعمل، أما التوظيف الذى يتم عن طريق تعيين أبناء العاملين أو التعيين المباشر فهو يفتح أبواب أمام المات

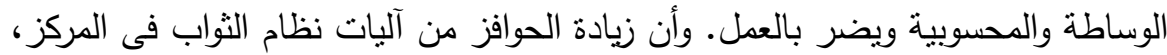
كما أن هناك آليات ثواب أخرى غير زيادة الحوافز والترقية والإجازة بأجر وذلك منل بأل

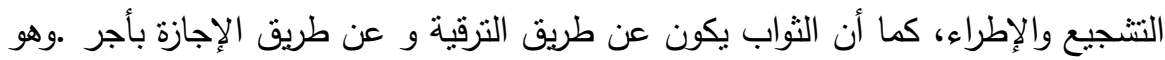

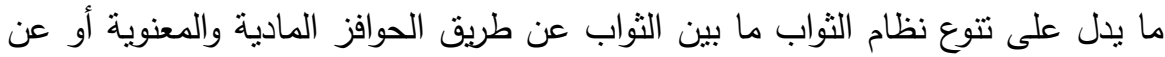
طريق الترقية وهى حوافز لها أهميتها فى تتمية الموارد البشرية ـ كما تلفت هذه التحليلات إلى أهمية الحوافز المادية فى تحسين جودة العمل وعدم الاقتصار على الحوافز المعنوية فقط ـ. وأن معيار الكفاء فى العمل هو التفانى فى العمل، يليه الابتكار والإبداع، ثم اللباقة، يلى ذلك أثياء أخرى مثل إنجاز العمل فى كل الظروف والتعامل الجيد مع المتابعين والرؤساء .وهو ما يثير إلى تتوع معيار الكفاءة وتفاوتها.

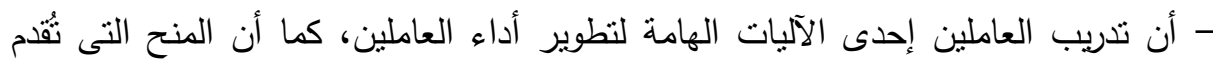

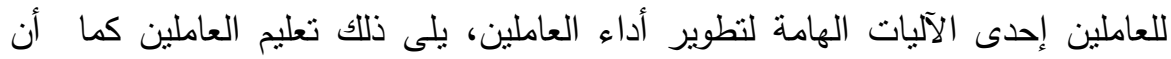

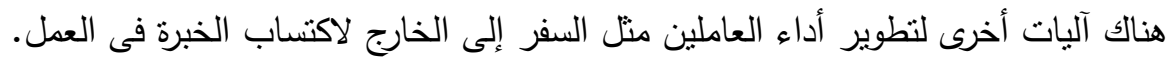


ويتفق هذا مع دراسة افوي زيتا جيزيل كونان ان هناك مجموعة من الكفاءات يحتاجها

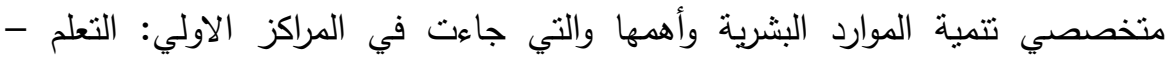

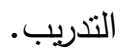

\section{x}

- الاهتمام بالعوامل والظروف البيئية المحيطة ببيئة العمل كالاضاءة المناسبة ودرجة الحرارة المناسبة والتهوية الجيدة. - ضرورة العمل علي توفير نادي اجتماعي للعاملين بالمركز يجتمع فيه العاملين واسرهم في

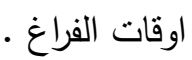

- الاهمام بالبحوث العلمية والرسائل المتتوعة التي تتم داخل المركز والعمل علي الاستفادة من نتائجها التي ينم التوصل اليها.

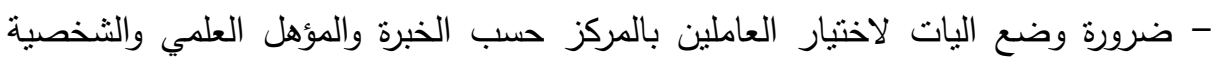
كذلك عمل مقابلات شخصية وامتحانات نظرية للمتقدمين للعمل بالمركز .

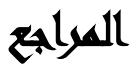

إقبال الأمير السمالوطي(9 . . ب): التخطيط بالمشاركة في مصر، دار المهندس للطباعة، القاهرة، ص م 1.

أسعد خطاب(^ . ץ): اقتصاديات تتمية الموارد البشرية، دار الكتاب الحديث، القاهرة حسين طه نجم وآخرون(£^191): البيئة والانسان "دراسات في الايكولوجيا البشرية"، وكالة

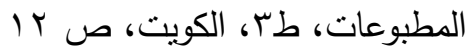

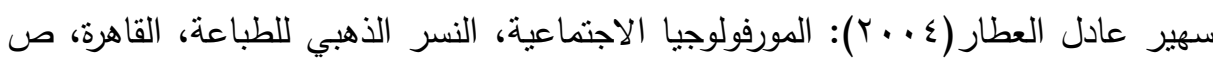
rr

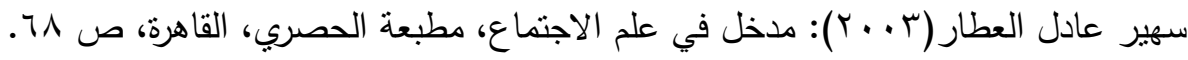

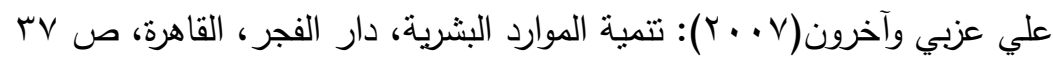




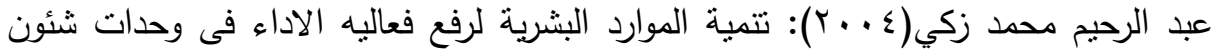

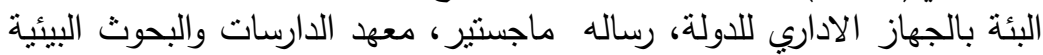

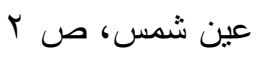

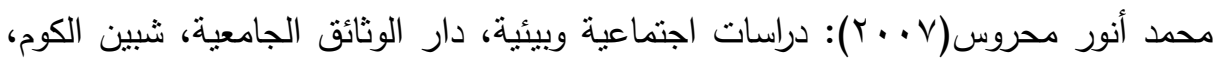

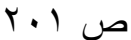

محمد أنور محروس(ي9 (1)): المعتقدات الدينية الثعبية ونمو الثقافات الفرعية المضادة،

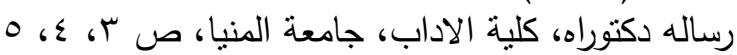

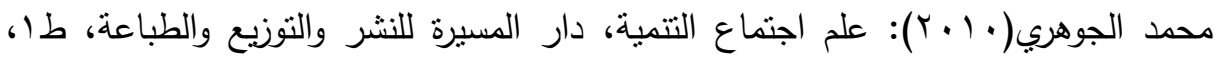
عمان، ص 9

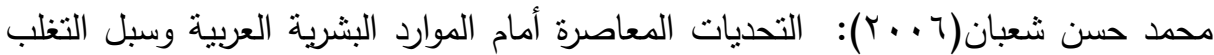

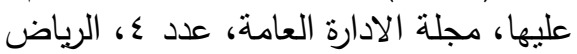

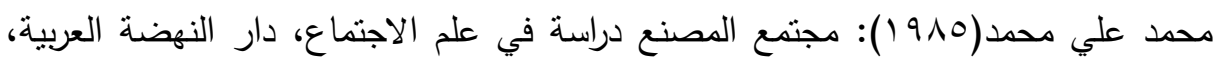

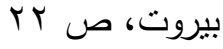

محمد عبد الغني حسن هلال(· (ب): مهارات ادارة الموارد البشرية، الجزء الثاني، مركز

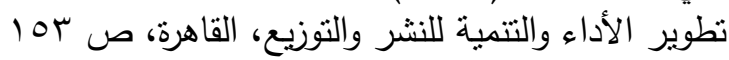

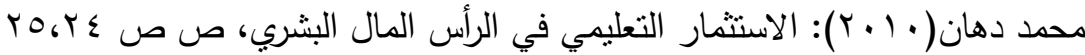
محمود يحيي سالم(1|(r): تتمية الموارد البشرية في ظل المتغيرات العالمية، المجموعة

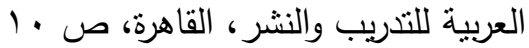

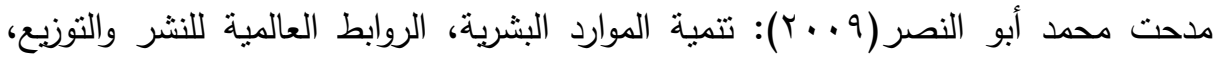
القاهرة، ص ع الو

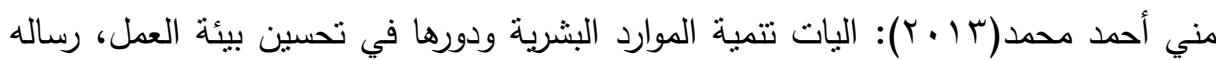
ماجسنير ، معهد الدارسات والبحوث البيئة، قسم التتمية الئة المنواصلة للبيئة وادادارة

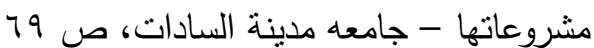

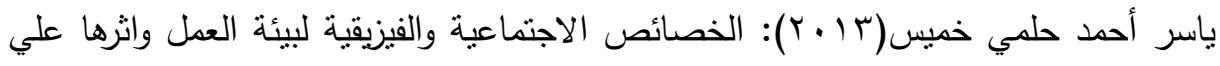
رضا العاملين، رساله دكتوراه، معهد الدراسات والبحوث البيئية، قسم العلوم الانسانية البيئية، جامعه عين شمس، صلئ صركاه

Human Development Report, New York, 1994. 
The HRD competencies as perceived by the human resources development professionals in banks in cote $\mathrm{d}$, lvoire, 2010 ,adissertation,presented to the college of graduate and professional studies, college of technology, Indiana state university, tterre haute, Indiana.

Leadership behaviors and human resource development in public sector organizations under conditions of organizational uncertainty: Comparative organizational study between U.S. and Korea, Song, Younhyun, 2008,State University of New York, in partial fulfillment of the requirements for the degree of Doctor of philosophy. 


\title{
THE IMPACT OF ENVIRONMENTAL AND
}

\section{CULTURAL CHARACTERISTICS ON THE} ACTIVATION OF HUMAN RESOURCES

\section{DEVELOPMENT-AFIELD STUDY ON THE DESERT}

\section{RESEARCH CENTER IN CAIRO GOVERNORATE}

\author{
Al-Attar, S. A. ${ }^{(1)}$; Mahrous, M. A. ${ }^{(2)}$; Taha, S. A. ${ }^{(3)}$ \\ and Abdou R. M. ${ }^{(4)}$
}

1) Girls College, Ain Shams University 2) Faculty of Arts, Helwan University 3) College of Commerce, Menoufia University

4) International Consultancy Center

\begin{abstract}
This study aimed to custom on the impact of environmental characteristics, culture, on the Activation of human resources development has been applied to the Desert Research Center of the Ministry of Agriculture area Ain Shams Cairo Governorate and that what distinguishes the center of the environmental nature of the (palace enriched in addition to the many green places and spaces dilated) and diversity cultural (staff from different environments and different provinces and the presence of two staff in covering all the qualifications and staff research includes registered for the master's and doctoral degrees and holding them) as well as many number of human resources, was chosen as a sample of 200 single 100 of the General staff and 100 research staff and has been using newspaper questionnaire In addition to conducting in-depth interviews with 20 single and use descriptive approach and the methodology of the case study was study concluded that the environmental and cultural characteristics of a strong impact on human resources as the widening, lighting, entry of the sun to the place affects the nature of the individual and help him to complete the work 174
\end{abstract}

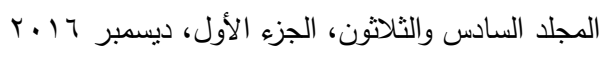


effectively and that good relations between colleagues The presidents of social and cultural rapprochement between them helps to good performance and efficiency to work and he has to be a plan for the development of human resources from the beginning of the appointment to the pension and provide social, cultural and educational health services for employees. 